\title{
Facile synthesis of biomass-based carbon materials nano-Ni- based catalysts and its application in selective hydrogenation of alkynes
}

\author{
Jiangmin Sun ${ }^{\mathrm{a}, \mathrm{c}}$, Jianguo Liu ${ }^{\mathrm{b} *}$, Longlong $\mathrm{Ma}^{\mathrm{b}}$ \\ ${ }^{a}$ CAS Key Laboratory of Renewable Energy, Guangdong Provincial Key Laboratory of New and \\ Renewable Energy Research and Development, Guangzhou Institute of Energy Conversion, \\ Chinese Academy of Sciences, Guangzhou 510640, P. R. China. \\ ${ }^{\mathrm{b}}$ Key Laboratory of Energy Thermal Conversion and Control of Ministry of Education, School of \\ Energy and Environment, Southeast University, Nanjing 210096, PR China. \\ c School of Energy Science and Engineering, University of Science and Technology of China, Hefei \\ 230026 P. R. China. \\ * Corresponding author: liujg@ @seu.edu.cn
}

\begin{abstract}
The development of high efficiency, excellent selectivity, and super activity metal catalyst for chemical selective hydrogenation of alkynes to olefin is of great significance in the field of the chemical industry. At the same time, the development of a large number of available base metal catalysts for organic conversion remains an important objective of chemical research. Herein, we report a facile preparation of a simple, high catalytic activity, environmentally friendly, and inexpensive biomass carbon material supported nano-nickel catalyst from lignin residue. The entire preparation process of the catalyst is simple, reliable, economical, and environmentally friendly, which provides a potential utilization prospect for large-scale industrial applications of biomass-based carbon material catalysts. Biomass-based lignin residues can not only reduce the high oxidation state of nickel ions into nickel nanoparticles by the in-situ reducing gas generated during the calcination process, but the mesoporous structure of lignin residue also promotes the adsorption of nickel metal, which greatly improved the catalytic activity of biomass-based Ni-based catalysts. The simple synthetic green, cost-effective and sustainable biomass-based Ni-based catalyst shows good performance in the selective hydrogenation of phenylacetylene, reaching $97.2 \%$ conversion and $84.3 \%$ styrene selectivity, respectively.
\end{abstract}

Key Words: Biomass carbon materials; Lignin; non-noble Ni based catalyst; selective hydrogenation; Phenyl acetylene

\section{Introduction}

Styrene is an important monomer of synthetic resin, ion exchange resin, and synthetic rubber in the polymerization industry. However, a small amount of benzene acetylene is often present in styrene raw materials. Benzene acetylene is toxic to the polymerization catalyst, and the maximum acceptable limit is not more than $10 \mathrm{ppm}^{1-9}$. Therefore, the removal of benzene acetylene in styrene raw materials is very important. At present, benzene acetylene impurities are mainly removed by selective hydrogenation to styrene in industry, but it is necessary to prevent the overhydrogenation of benzene acetylene to ethylbenzene at the same time. Therefore, the selective hydrogenation of benzene acetylene to olefin has very important practical significance ${ }^{10,11}$.

In the process of developing low cost, high activity, and high selectivity catalysts for selective hydrogenation of benzene acetylene ${ }^{12}$. How to combine high activity and selectivity of catalysts has been a major challenge in this field. Metals with catalytic 
activity for alkyne hydrogenation are mainly $\mathrm{Pd}^{13}, \mathrm{Au}^{14}, \mathrm{Ni}^{15}, \mathrm{Fe}^{16-18}, \mathrm{Pt}^{19}$, and $\mathrm{Cu}^{20}$. In recent years, the research on catalysts for selective hydrogenation of alkynes has been further deepened, and the research direction has shifted to the development of more environmentally friendly and efficient catalysts. There are mainly two kinds of hydrogenation catalysts: One is the noble metal catalyst, such as $\mathrm{Pt}^{21-24}, \mathrm{Pd}^{25-27}$ based alloy nanoparticles, etc. The other is non-noble transition metal catalysts such as Raney $\mathrm{Ni}{ }^{28-33}, \mathrm{Cu}^{34-37}$ catalyst, etc. Among the noble metal catalysts, supported Pd catalyst has a high conversion rate for selective hydrogenation of phenylacetylene ${ }^{38}$. While for the non-noble metal catalysts, Ni-based catalysts are typical, which have attracted much attention due to their low cost and good catalytic hydrogenation performance ${ }^{39-41}$. Donphai $^{42}$ reported the synthesis of a mesoporous silica (MS) support Ni-carbon nanofibers (CNFs) catalyst. First, the MS support was prepared by modifying the pore size of SBA-15 mesoporous silica using a swelling agent, 1,3,5-trimethylbenzene (TMB). After that, nickel nanoparticles were loaded onto the MS support via an impregnation method, and Ni- CNFs were consecutively synthesized using nickel nanoparticles in the catalytic chemical vapor deposition (CCVD) process. The obtained $\mathrm{Ni}-\mathrm{CNF} / \mathrm{MS}$ catalyst with unique composite structure, which shows excellent catalytic performance than Ni/MS. Panwar ${ }^{43}$ synthesized polyaniline/graphene oxide composites by liquid-liquid interface polymerization of aniline in a sulfonated graphene oxide suspension using hydrogen peroxide and ferric chloride as oxidants. Nanonickel was then decorated on the synthetic hybrid material and used for hydrogenation of phenylene and its derivatives at room temperature and hydrogen pressure. And the yield of styrene reached $82 \%$. The synthesized hybrid catalyst had good catalytic activity and was recovered by centrifugation at the end of the reaction. There was no obvious loss of catalytic activity after several cycles. Using $\mathrm{SiH}_{4}$ as a silicon source, $\mathrm{Chen}^{44}$ prepared nickel-silicon intermetallic compounds by direct silicification. The interaction between nickel and silicon in nickel silicide led to a strong modification of the electronic structure around the Fermi level compared to the metallic $\mathrm{Ni}$, which caused good selective hydrogenation of phenylacetylene to styrene. Using carbon template, silicide oxides, and $\mathrm{SiH}_{4} / \mathrm{H}_{2}$, Chen ${ }^{45}$ successfully synthesized nano-silicide modified nickel catalyst with significant catalytic activity and high selectivity for hydrogenation of benzene acetylene. The XRD, magnetic measurements, HRTEM, and EDX confirmed the formation of NiSix which involved the following sequence: $\mathrm{Ni}$ (cubic) $\rightarrow \mathrm{Ni}_{2} \mathrm{Si}$ (orthorhombic) $\rightarrow \mathrm{NiSi}$ (orthorhombic) $\rightarrow \mathrm{NiSi}_{2}$ (cubic), with the increasing siliconized temperatures. They found that $\mathrm{Si}$ atoms reside in the gaps between $\mathrm{Ni}$ atoms, which changed the crystal lattice of the nickel unit cell and further affected the activity of the catalyst and the selectivity of the product. As it is well known that the catalyst's support has a great effect on the catalytic reactivity, stability, and selectivity. Hence, the development of a cost-effective, more stable, and sustainable support carrier is of great importance.

Carbon materials, which serve as common catalyst carriers, have been widely used and showed comparable stability, cost-effectiveness, and excellent efficiency in both academia and industry. Biomass, as a kind of abundant, low-cost, and green carbon source, can be prepared as carbon material and used as catalysts' carriers. There are two main methods for preparing carbon materials from biomass. One is the step-by-step preparation method including two steps processes. First, the biomass is prepared into porous carbon material through high-temperature activation decomposition, and then the required metal is loaded on the carbon material through the calcination method. The carbon material prepared by this method has better properties including larger specific surface area and multiple pore structures than the commercial activated carbon. Zhang ${ }^{46}$ 
prepared microporous carbon materials using corn stalks, straw, and pine needles as the initial raw materials and $\mathrm{KOH}$ as the activator. The characterization showed that the specific surface area of the carbon materials was more than $3000 \mathrm{~m}^{2} / \mathrm{g}$. Subsequently, Pt was loaded on the prepared carbon materials and then applied in the hydrogenation of cinnamaldehyde. They found that the catalyst showed better stability than the commercial carbon-supported catalyst during the catalyst's recycling test. The carbon materials prepared by biomass had more oxygen-containing functional groups and diverse pore structures, which were beneficial to the dissipation of reaction heat and prevented the sintering of the catalyst. The second method is in situ carbonization preparation, in which the precursor of carbon carrier is mixed with active phase metal salt and calcined at a certain temperature in an inert atmosphere. This method generally uses simple carbon-containing compounds as carbon sources, such as polyethylene glycol, melamine, and so on. Recently, the use of biomass as a carbon source to prepare carbon-based catalysts in situ has received more and more attention from researchers due to its cost-effective and environmental benefits. For example, Zhang and coworkers ${ }^{47}$ used cotton as a carbon source and mixed it with nickel nitrate solution to prepare $\mathrm{Ni} / \mathrm{C}$ catalyst through calcination at high temperature, then they applied it in the hydrogenation of o-chloronitrobenzene. Under $0.5 \mathrm{Mpa}$ pressure of $\mathrm{H}_{2}$, the yield of chloroaniline could reach up to $100 \%$. They used $\mathrm{H}_{2}$ instead of inert gases in the catalyst's preparation process. Later, Duan and co-workers ${ }^{48}$ prepared the Co@NPC in a sequential hydrothermal and pyrolysis procedure starting from the bamboo shoots as raw materials. And the prepared shell Co@C catalyst doped with N and P showed excellent activity and selectivity for the hydrogenation of functionalized nitroarenes. In addition, the catalyst also exhibited high stability and could be recovered easily due to its magnetic properties. Lignin, as one of the most naturally abundant polymer materials extracted from biomass, has been poorly utilized as additives in building materials, basic raw materials for preparing low-value products like phenolic resins, and chemical monomers. Moreover, the large amounts of lignin produced from the pulp and paper industry were treated as waste and generated serious pollution to the environment. Developing a variety of methodologies for the utilization of lignin can not only provide a potential application of lignin but also release the environmental problems caused by lignin waste. Recently, the carbon materials prepared from lignin have been widely used in water or air purification, aerogels, and energy storage, due to their low cost, good thermal stability, high carbon content $(60 \%)$, and a large number of benzene ring structures.

Here, we reported the preparation of carbon-supported non-noble Ni catalyst starting from biomass lignin raw material. The starting biomass materials and pretreatment of lignin had a great effect on the catalytic physical properties and catalytic reactivity in the selective hydrogenation of alkyne. Under the optimized mild reaction conditions $\left(2 \mathrm{Mpa} \mathrm{H}_{2}, 80^{\circ} \mathrm{C}, 5 \mathrm{~h}\right)$, the optimized catalyst $\mathrm{Ni} / \mathrm{C}_{\mathrm{LW}}$ prepared from washed lignin in situ calcination without any addition $\mathrm{H}_{2}$ reducing atmosphere showed excellent conversion of $97 \%$ and $87 \%$ selectivity in the selective hydrogenation of terminal alkynes. Moreover, the catalyst had good stability and can be reused 5 times without losing significant reactivity and selectivity. It also opens the potential application of biomass carbon materials from lignin directly for heterogeneous catalysis in industry, which is a cost-effective and green environmentally friendly process.

\section{Experimental Section}

\subsection{Synthesis of catalysts}


We prepared three kinds of catalysts with different carbon materials as support, namely shaddock peel, lignin, and washed lignin. Removed the yellow skin of shaddock peel, cut the white part into strips, and freeze-dried it for $48 \mathrm{~h}$ in a freeze dryer. After freeze-drying, put it into a crusher and break it into powder. Took $0.378 \mathrm{~g}$ $\mathrm{Ni}\left(\mathrm{NO}_{3}\right)_{2} \cdot 6 \mathrm{H}_{2} \mathrm{O}$ and dissolve it in $15 \mathrm{ml}$ deionized water. $2 \mathrm{~g}$ shaddock peel powder was added to the stirring nitrate solution and stirred at $50{ }^{\circ} \mathrm{C}$ until dry. Then the samples were further dried for $12 \mathrm{~h}$ in an oven at $100{ }^{\circ} \mathrm{C}$. The dried samples were roasted in a nitrogen muffle oven under an $\mathrm{N}_{2}$ atmosphere. The roasting procedure was: the temperature was $400{ }^{\circ} \mathrm{C}$, the heating rate was $2{ }^{\circ} \mathrm{C} / \mathrm{min}$, and the roasting temperature was kept for $3 \mathrm{~h}$ after rising to the preset temperature. Then we got the catalyst supported by shaddock peel( $\left.\mathrm{Ni} / \mathrm{C}_{\mathrm{SP}}\right)$. In the same way, as shown above, we used lignin residue and water-washed lignin residue as the carrier to obtain $\mathrm{Ni} / \mathrm{C}_{\mathrm{L}}$ and $\mathrm{Ni} / \mathrm{C}_{\mathrm{LW}}$.

\subsection{Catalyst characterization}

The hydrogenation products were recorded by GC-2014C (Shimadzu, Japan) with an HP5 column $(30 \mathrm{~m} \times 250 \mathrm{~mm} \times 0.25 \mu \mathrm{m})$ and an FID detector. GC-MS of products was determined by TRACE 1300ISQ GC-MS (Thermo Fisher Scientific, America) with TG-5MS column $(30 \mathrm{~m} \times 250 \mathrm{~mm} \times 0.25 \mu \mathrm{m}) .{ }^{1} \mathrm{H}$ NMR of products was recorded on a Bruker Avance III (400 MHz) spectrometer (Bruker BioSpin, Germany) with $\mathrm{CDCl}_{3}$ as solvent at $400 \mathrm{MHz}$. The TEM measurements were conducted on a JEM-2100F microscope (JEOL, Japan) operated at $200 \mathrm{kV}$. The SEM images were obtained on Analytical SEM SU-70 (Hitachi, Japan) microscope operated at $10 \mathrm{kV}$. XRD powder patterns were recorded on an X'Pert Pro MPD diffractometer (PANalytical, Netherlands) using the $\mathrm{Cu} K \alpha$ radiation at $40 \mathrm{kV}$ and $20 \mathrm{~mA}(\lambda=1.5406 \AA)$. Processing and assignments of the powder patterns were conducted on the software Jade 6.0 using the Powder Diffraction File (PDF) database of the International Centre of Diffraction Data (ICDD). Nitrogen adsorption isotherms were measured at $-196{ }^{\circ} \mathrm{C}$ on a Quadrasorb SI nitrogen adsorption apparatus (Quantachrome, America) by using the BET method.

\subsection{Hydrogenation of alkyne in a batch reactor}

The reaction was conducted in a stainless-steel autoclave (Shanghai Yanzheng Experimental Instrument Co., Ltd. China) with one well (50 $\mathrm{mL}$ per well), one thermocouple, and one circulating water-cooling equipment. A glass reaction tube was added to the reaction kettle, which was equipped with a $10 \mathrm{~mm}$ magnetic stir bar, 0.5 mmol phenylacetylene, $10 \mathrm{mg}$ catalyst, and $6 \mathrm{ml}$ solvent. After that, the reactor was sealed and purged with $\mathrm{H}_{2}$ three times, and then the reactor was filled with hydrogen to the set pressure value. Put the reactor into the heating mantle and set the stirring speed to $300 \mathrm{rpm}$. Preheated the reactor from room temperature to the set reaction temperature (internal temperature detected by a thermocouple) at a heating rate of $2{ }^{\circ} \mathrm{C} / \mathrm{min}$. After the reaction, the reaction kettle was cooled to room temperature, and the remaining gas was discharged, and then the reaction solution was collected with a dropper and filtered. The catalyst was immobilized on the magnetic stirring bar and washed thoroughly with ethanol and water. The catalyst (together with magnetic stirring bar) was then dried at $-48^{\circ} \mathrm{C}$ for $12 \mathrm{~h}$ in a vacuum using a freeze dryer. The reaction products were identified by GC-MS and ${ }^{1} \mathrm{H}$ NMR. The yields of reaction products were determined by $\mathrm{GC}$ with 1,3,5-trimethoxybenzene as internal standard. For the ${ }^{1} \mathrm{H}$ NMR analysis, $2 \mathrm{~mL}$ reaction solutions were concentrated by rotary evaporation and then added with $0.6 \mathrm{~mL}$ of $\mathrm{CDCl}_{3}$ (pre-neutralized with basic $\mathrm{Al}_{2} \mathrm{O}_{3}$ ) for analysis. 


\section{Results and discussion}

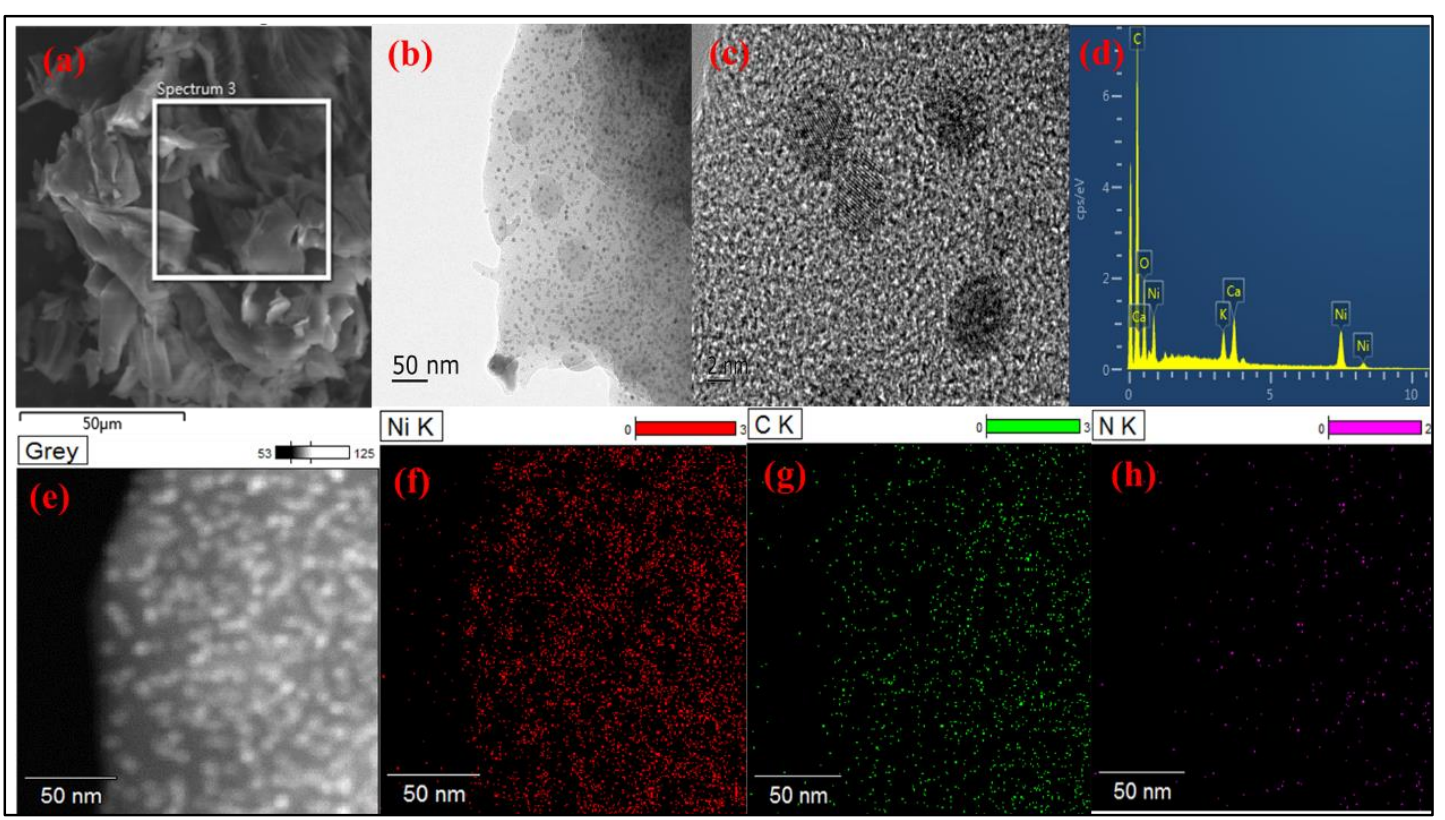

Figure 1. Representative SEM image of Ni/C $\mathrm{C}_{\mathrm{L}}$ (a); representative HAADF-TEM images of $\mathrm{Ni} / \mathrm{C}_{\mathrm{L}}$ (b, c); energy spectrum image of $N i / C_{L}(d)$ and the mapping images of $N i / C_{L}(e-h)$.
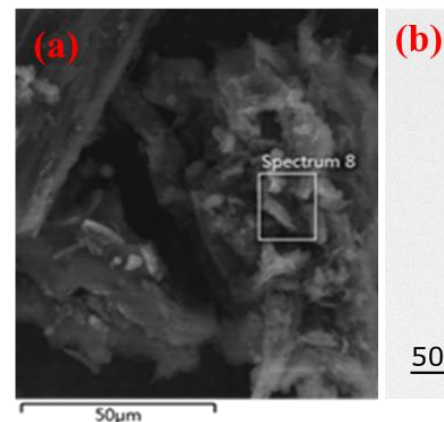

(b)
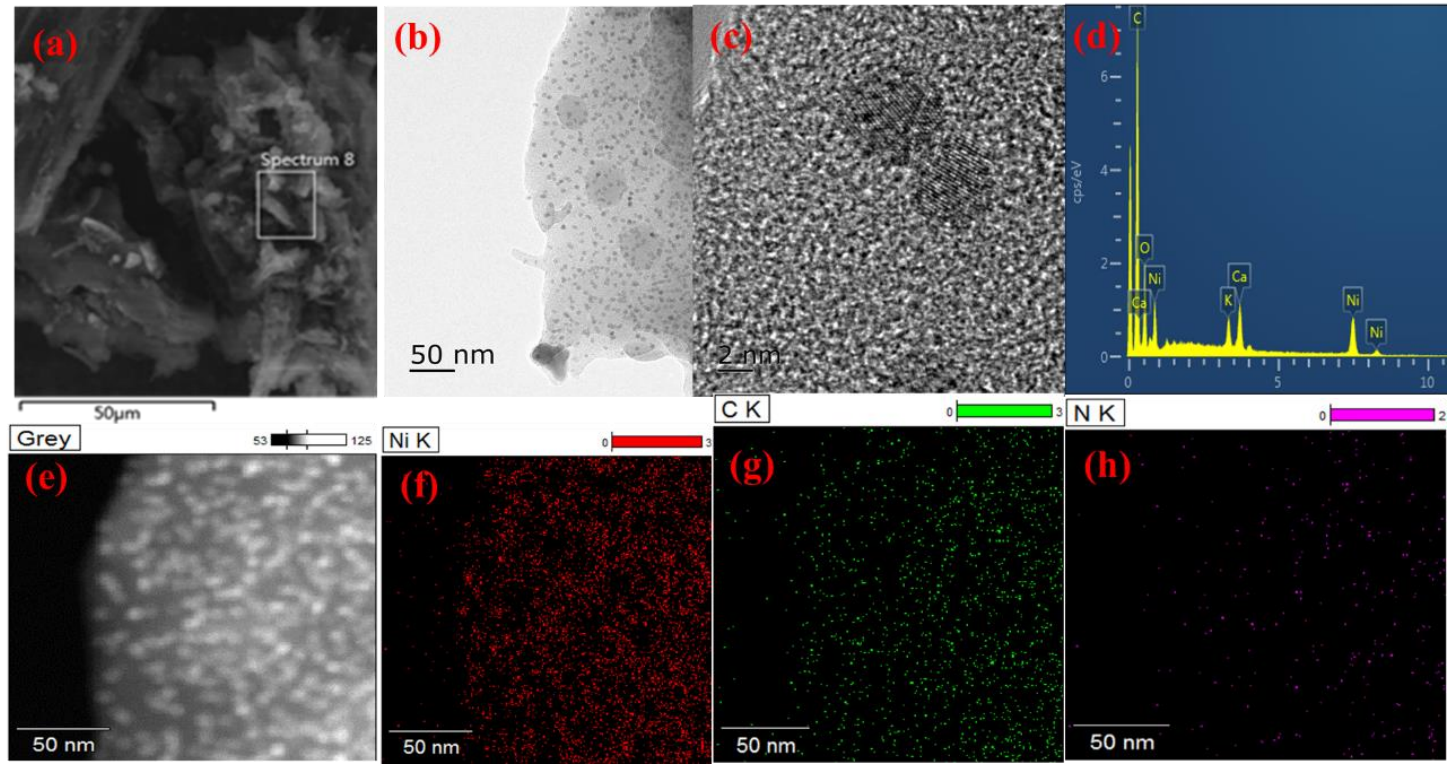

Figure 2. Representative SEM image of $\mathrm{Ni} / \mathrm{C}_{\mathrm{LW}}$ (a); representative HAADF-TEM images of $\mathrm{Ni} / \mathrm{C}_{\mathrm{LW}}$ $(b, c)$; energy spectrum image of $\mathrm{Ni} / \mathrm{C}_{\mathrm{LW}}(\mathrm{d})$; the mapping images of $\mathrm{Ni} / \mathrm{C}_{\mathrm{LW}}(\mathrm{e}-\mathrm{h})$.
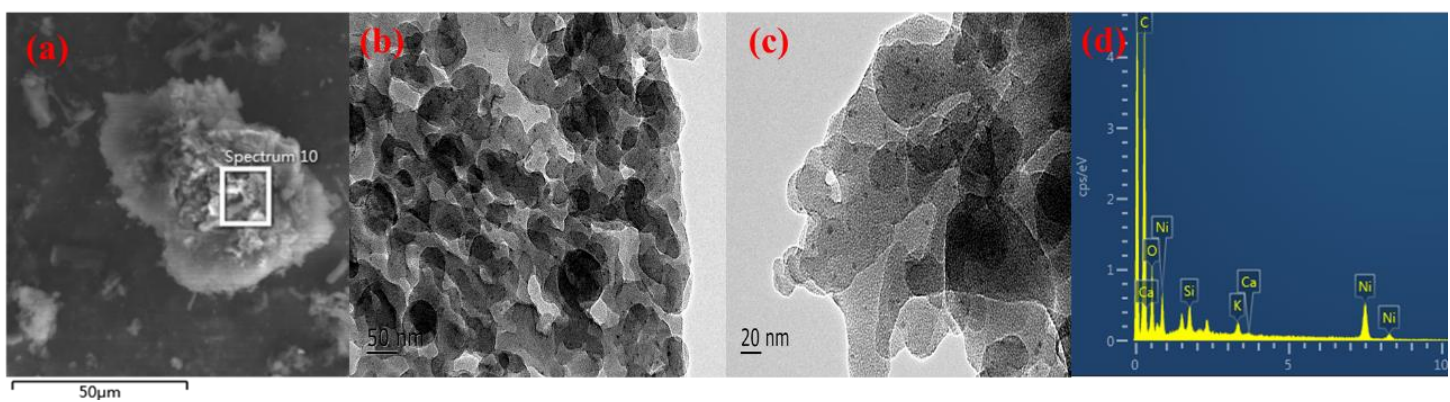

Figure 3. Representative SEM images of Ni/C $\mathrm{C}_{\mathrm{SP}}(\mathrm{a})$; representative HAADF-TEM images of Ni/C $\mathrm{CP}_{\mathrm{SP}}$ $(b, c)$; energy spectrum image of $\mathrm{Ni} / \mathrm{C}_{\mathrm{SP}}(\mathrm{d})$. 
As shown in the representative scanning electron microscopy (SEM) images and transmission electron microscope (TEM) images (Figure 1-3), the structure and morphology of the carbon material-supported Ni-based metal catalysts prepared in situ with different biomass raw materials, shaddock peel, and lignin, or lignin pretreatment methods such as washed lignin were very different. The $\mathrm{Ni} / \mathrm{C}_{\mathrm{L}}$ and $\mathrm{Ni} / \mathrm{C}_{\mathrm{LW}}$ catalysts, which were prepared from lignin and washed lignin respectively, had dense lamellar and rod-like structures similar to petals, respectively. In addition, the nickel particles were uniformly distributed in the carrier and wrapped by the carbon shell, so that the catalyst had good reaction activity and stability under harsh reaction conditions. However, in the $\mathrm{Ni} / \mathrm{C}_{\mathrm{SP}}$ catalyst prepared from the shaddock peel, the nickel particles were not dispersed evenly in the carrier, but gathered together, which could reduce the stability and reactivity of the catalysts.

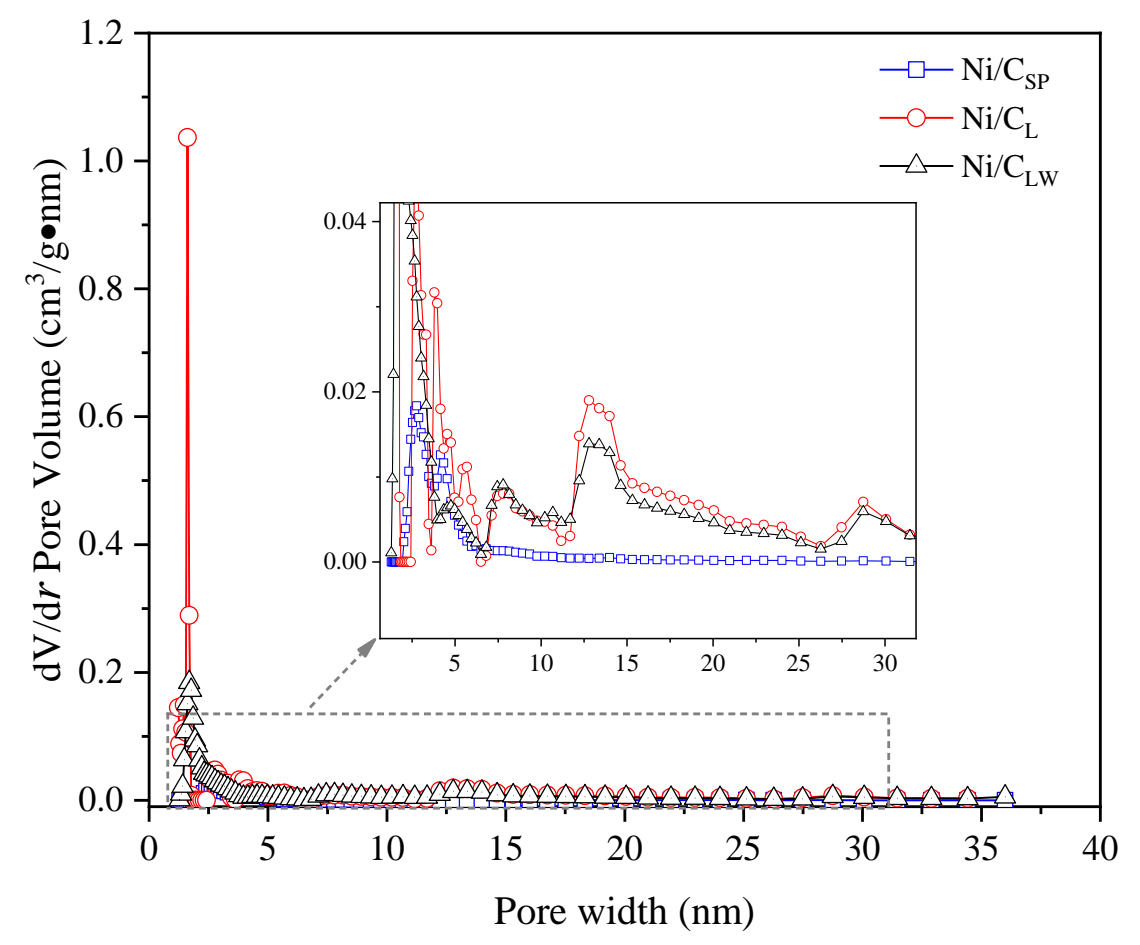

Figure 4. Representative BET measurements of $\mathrm{N}_{2}$ adsorption and desorption isotherm curves and pore size distribution profile of catalysts

Table1. Physicochemical properties of catalysts

\begin{tabular}{cccc}
\hline Samples & $\mathrm{S}_{\mathrm{BET}}\left(\mathrm{m}^{2} / \mathrm{g}\right)$ & $\mathrm{P}_{\mathrm{v}}\left(\mathrm{cm}^{3} / \mathrm{g}\right)$ & $\mathrm{P}_{\mathrm{d}}(\mathrm{nm})$ \\
\hline $\mathrm{Ni} / \mathrm{C}_{\mathrm{sp}}$ & 16.461 & 0.023 & 13.845 \\
$\mathrm{Ni} / \mathrm{C}_{\mathrm{L}}$ & 236.624 & 0.232 & 8.068 \\
$\mathrm{Ni} / \mathrm{C}_{\mathrm{LW}}$ & 76.727 & 0.146 & 8.440 \\
\hline
\end{tabular}


The BET surface areas of these different catalysts were detected by $\mathrm{N}_{2}$ adsorption with an adsorption analyzer (Tristar II 3020 volumetric) (Figure 4, Table1). Before $\mathrm{N}_{2}$ adsorption measurements, the samples were evacuated at $200{ }^{\circ} \mathrm{C}$ for $12 \mathrm{~h}$. And the specific surface area was calculated by the BET method. The average pore diameters and pore volumes were calculated by the BJH method with the desorption branches of the isotherms. The pore structure of carbon-supported Ni-based metal catalysts prepared in situ from different biomass materials had obvious differences. We could see that they all had distinct microporous structures. These mesoporous structures might promote the transfer process of reaction raw materials, and at the same time promote the diffusion process of the products. The average pore diameter of the $\mathrm{Ni} / \mathrm{C}_{\mathrm{SP}}$ catalyst was $13.85 \mathrm{~nm}$, and the pore structure was very close to the loose structure, which was consistent with the dense structure in the above-mentioned SEM analysis. The average pore volume of $\mathrm{Ni} / \mathrm{C}_{\mathrm{SP}}$ was lower than $\mathrm{Ni} / \mathrm{C}_{\mathrm{LW}}$, but the average pore size of $\mathrm{Ni} / \mathrm{C}_{\mathrm{SP}}$ was higher than $\mathrm{Ni} / \mathrm{C}_{\mathrm{LW}}$, indicating a partial blockage of pores in $\mathrm{Ni} / \mathrm{C}_{\mathrm{SP}}$.

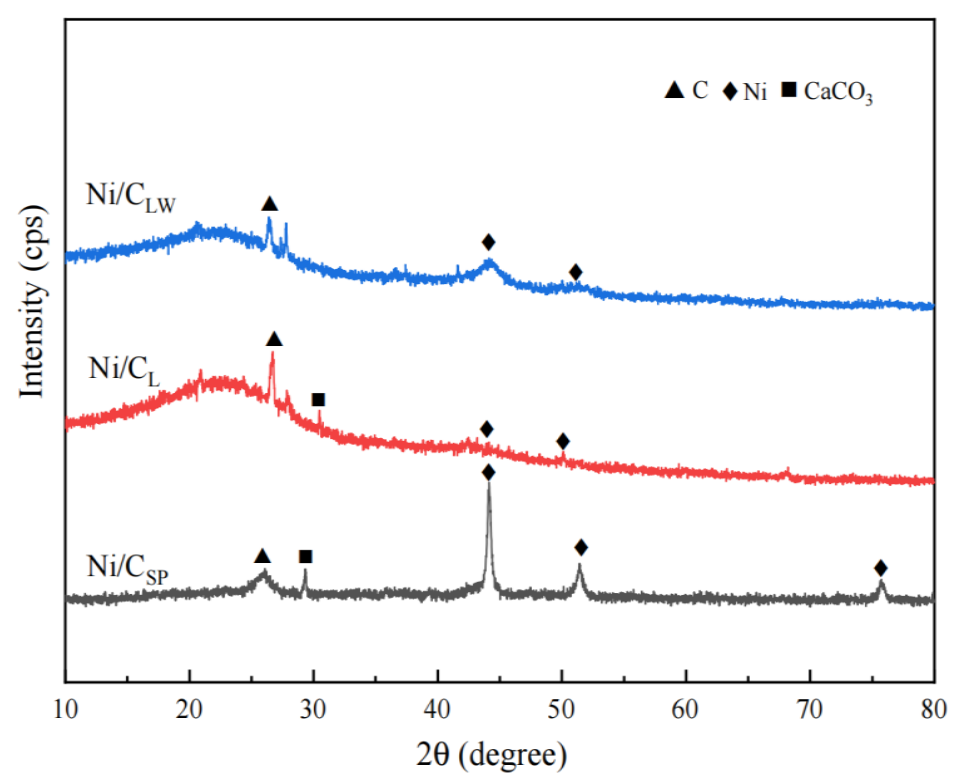

Figure 5. $\mathrm{XRD}$ patterns of $\mathrm{Ni} / \mathrm{C}_{\mathrm{LW}}, \mathrm{Ni} / \mathrm{C}_{\mathrm{SP}}$, and $\mathrm{Ni} / \mathrm{C}_{\mathrm{L}}$ catalysts

As shown in the XRD patterns of these three catalysts (Figure 5), the starting materials of the biomass had a great effect on the catalysts' structure and metal dispersions. The catalyst $\mathrm{Ni} / \mathrm{C}_{\mathrm{SP}}$ prepared from the shaddock peel gave the highintensity peaks of Ni nanoparticles at $2 \theta=44.6^{\circ}, 52.0^{\circ}$ and $76.6^{\circ}$, which indicated that the Ni nanoparticles were not well dispersed like the other two catalysts $\mathrm{Ni} / \mathrm{C}_{\mathrm{WL}}$ and $\mathrm{Ni} / \mathrm{C}_{\mathrm{L}}$. For the catalysts $\mathrm{Ni} / \mathrm{C}_{\mathrm{WL}}$ and $\mathrm{Ni} / \mathrm{C}_{\mathrm{L}}$ prepared from lignin, we could not observe high-intensity peaks of Ni-alloy, which showed that Ni nanoparticles had very good dispersion on these two catalysts. Other than that, we could also observe a broad peak of graphitic carbon shell peak at around $20^{\circ}-30^{\circ}$, and this phenomenon was in accordance with the above-mentioned TEM analysis. In the XRD patterns of $\mathrm{Ni} / \mathrm{C}_{\mathrm{SP}}$ and $\mathrm{Ni} / \mathrm{C}_{\mathrm{L}}$ catalysts, we could also observe the diffraction peak of $\mathrm{CaCO}_{3}$ species located at $29.6^{\circ}$. This is because shaddock peel and lignin are both renewable biomass resources in nature and contain Ca elements, when they are used to prepare the carbonsupported Ni-based catalysts in situ, the small amount of the Ca element can still be retained. However, the carbon-supported Ni-based catalyst prepared from washed lignin did not show the diffraction peak of the $\mathrm{Ca}$ element, which indicated that the pretreatment process of lignin had removed $\mathrm{Ca}$ element to a certain extent. 


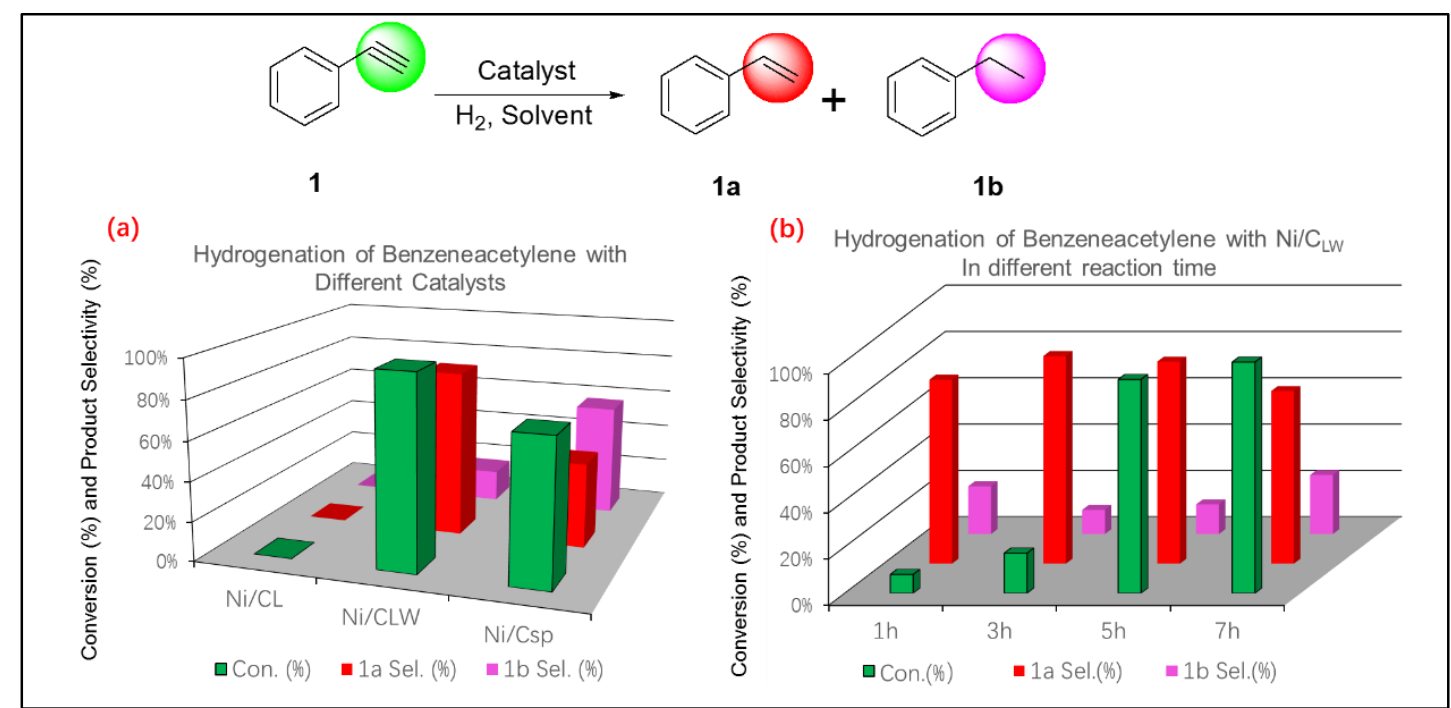

Figure 6. Selective hydrogenation of phenylacetylene. (a) Reaction conditions: $0.5 \mathrm{mmol}$ Phenyl acetylene, $5 \mathrm{mg}$ catalyst, $4 \mathrm{ml}$ of $\mathrm{MeOH}, 2 \mathrm{Mpa}_{2}, 80^{\circ} \mathrm{C}, 4 \mathrm{~h}$.; (b) Reaction conditions: $0.5 \mathrm{mmol}$ Phenyl acetylene, $5 \mathrm{mg}$ catalyst, $4 \mathrm{ml}$ of $\mathrm{MeOH}, 1-4 \mathrm{Mpa} \mathrm{H}_{2}, 80{ }^{\circ} \mathrm{C}, 4 \mathrm{~h}$. The conversion and selectivity were determined by GC or NMR spectroscopy using an internal standard or as reported in the literature.

After the synthesis of these three biomass-based nickel catalysts, we evaluated their catalytic reactivity in the selective hydrogenation of benzene acetylene. As shown in Figure 6, the catalysts $\mathrm{Ni} / \mathrm{C}_{\mathrm{L}}, \mathrm{Ni} / \mathrm{C}_{\mathrm{SP}}$, and $\mathrm{Ni} / \mathrm{C}_{\mathrm{LW}}$ which were prepared from the different biomass raw materials, shaddock peel and lignin, or different lignin pretreatment methods had a great difference in catalytic reactivity and product selectivity in selective hydrogenation of benzene acetylene. Under the selected reaction conditions $\left(2 \mathrm{Mpa}_{2}, 80^{\circ} \mathrm{C}, 4 \mathrm{~h}\right)$ (Figure 6a), only the $\mathrm{Ni} / \mathrm{C}_{S P}$ and $\mathrm{Ni} / \mathrm{C}_{\mathrm{LW}}$ two catalysts showed better catalytic reactivity. The conversion rates and products selectivity of 1a reached $78 \%$ conversion, $42 \%$ selectivity, and $97 \%$ conversion, $84 \%$ selectivity respectively. However, the $\mathrm{Ni} / \mathrm{C}_{\mathrm{L}}$ catalyst prepared by in-situ reduction of $\mathrm{Ni}$ salt supported by lignin showed no reactivity, and the raw materials did not change before and after the reaction. Since the $\mathrm{Ni} / \mathrm{C}_{\mathrm{LW}}$ catalyst showed better conversion of benzene acetylene and the desired product 1a selectivity, we further evaluated it under a variety of reaction conditions. As shown in Figure $\mathbf{6 b}$, when the reaction time was $3 \mathrm{~h}$ and below, the raw materials were not completely transformed, but when the reaction time was longer than $7 \mathrm{~h}$, we could obtain a high amount of over-hydrogenation product. Finally, we managed to obtain good catalytic reactivity and 1a product selectivity with $92.3 \%$ conversion, $87.2 \%$ selectivity, and $97.2 \%$ conversion, $84.3 \%$ selectivity in $5 \mathrm{~h}$ and $4 \mathrm{~h}$ respectively. 


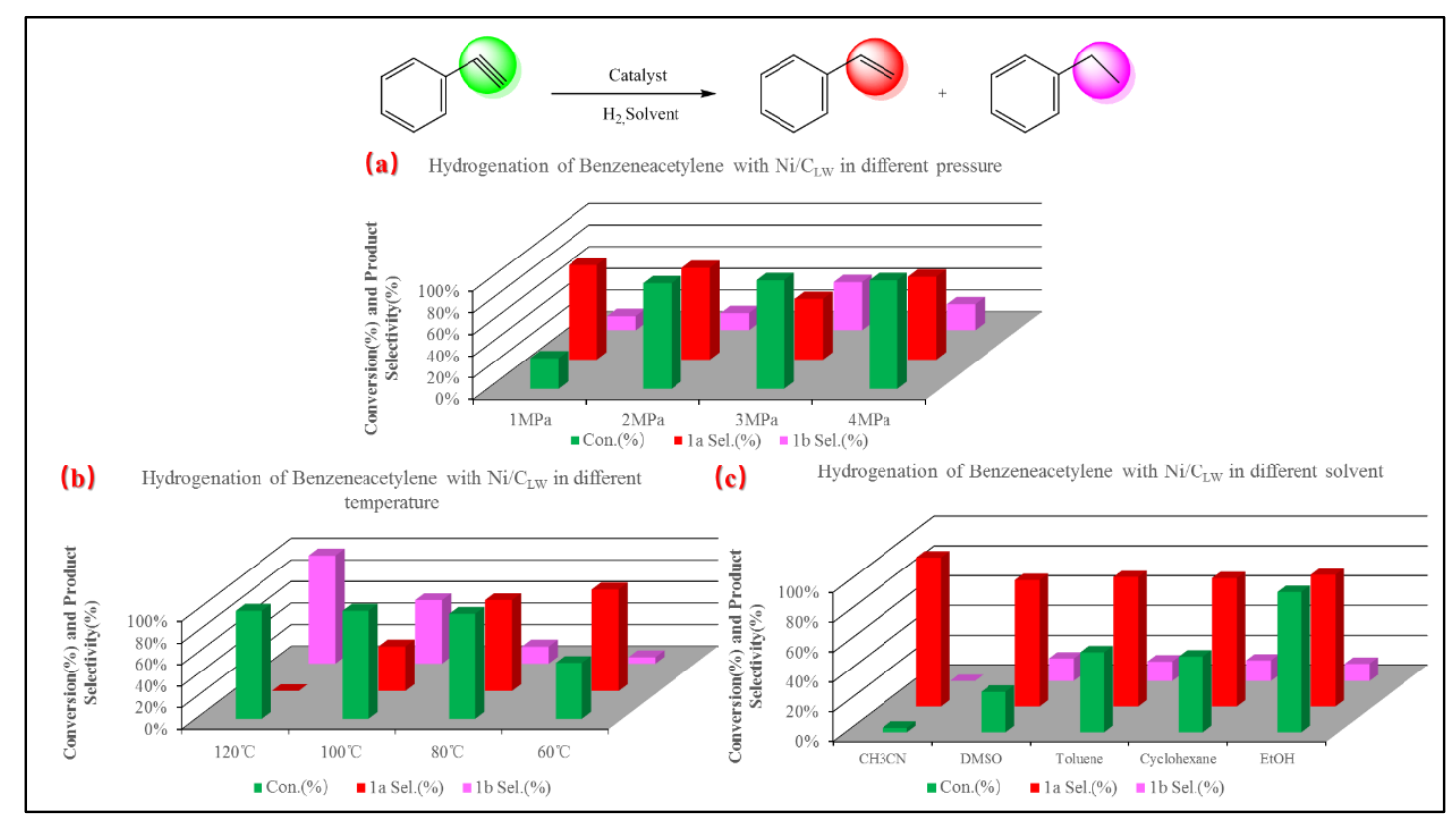

Figure 7. Selective hydrogenation of phenyl acetylene. (a) Reaction conditions: 0.5 mmol Phenyl acetylene, $5 \mathrm{mg}$ catalyst, $4 \mathrm{ml}$ of $\mathrm{MeOH}, 2 \mathrm{Mpa}_{2}, 60-120{ }^{\circ} \mathrm{C}, 4 \mathrm{~h}$; (b) Reaction conditions: 0.5 mmol Phenyl acetylene, $5 \mathrm{mg}$ catalyst, $4 \mathrm{ml}$ of $\mathrm{MeOH}, 2 \mathrm{Mpa} \mathrm{H}_{2}, 80{ }^{\circ} \mathrm{C}, 1,3,5,7,9 \mathrm{~h}$; (c) Reaction conditions: $0.5 \mathrm{mmol}$ Phenyl acetylene, $5 \mathrm{mg}$ catalyst, $4 \mathrm{ml}$ of solvent, $2 \mathrm{Mpa}, \mathrm{H}_{2}, 80{ }^{\circ} \mathrm{C}, 4 \mathrm{~h}$. The conversion and selectivity were determined by GC or NMR spectroscopy using an internal standard or as reported in the literature.

Then we evaluated the $\mathrm{H}_{2}$ pressure, reaction temperature and solvent for the selective hydrogenation of benzene acetylene. As shown in Figure 7a, when the reaction pressure increased from $1 \mathrm{Mpa}$ to $4 \mathrm{Mpa}$, the conversion increased from $28 \%$ to $100 \%$, and the selectivity of $1 \mathrm{a}$ decreased from $87 \%$ to $76 \%$. It could be seen that the selectivity of 1a decreased with the increase of hydrogen pressure. This was because the increase of hydrogen pressure caused the intermediate product styrene obtained from the reaction to be over-hydrogenated to benzene ethane, thereby reducing the selectivity of the styrene product. Overall, when the hydrogen pressure was $2 \mathrm{Mpa}$, the $\mathrm{Ni} / \mathrm{C}_{\mathrm{LW}}$ catalyzed selective hydrogenation of phenyl acetylene achieved better results in the conversion rate and product 1a selectivity. Then we further investigated the reaction temperature factor for the $\mathrm{Ni} / \mathrm{C}_{\mathrm{LW}}$ catalyzed selective hydrogenation of phenyl acetylene. As shown in Figure 7b, when the reaction temperature was increased from $60{ }^{\circ} \mathrm{C}$ to $120^{\circ} \mathrm{C}$, the reaction conversion increased to $100 \%$, but the selectivity of $1 \mathrm{a}$ gradually decreased. When the reaction temperature was $120^{\circ} \mathrm{C}$, we could only observe the over-hydrogenation products benzene ethane. When the reaction temperature was $80{ }^{\circ} \mathrm{C}$, the $\mathrm{Ni} / \mathrm{C}_{\mathrm{LW}}$ catalyzed semi-hydrogenated phenyl acetylene reaction had a good reaction effect, and the conversion rate and 1a selectivity reached $97 \%$ and $84 \%$, respectively. As shown in Figure7c, the solvent had a great effect on the transformation of phenyl acetylene. Among all the screening solvents, the polar and protic solvent EtOH gave the best results with $93.9 \%$ conversion and $88.4 \%$ 1a selectivity. Although the polar solvent $\mathrm{CH}_{3} \mathrm{CN}$ and DMSO also gave the excellent selectivity of 1a, the catalyst did not show good reactivity in these two solvents with a lower $20 \%$ conversion. The other two non-polar solvents toluene and cyclohexane gave a moderate conversion of $50 \%$ and excellent selectivity of 1 a with $80 \%$. 


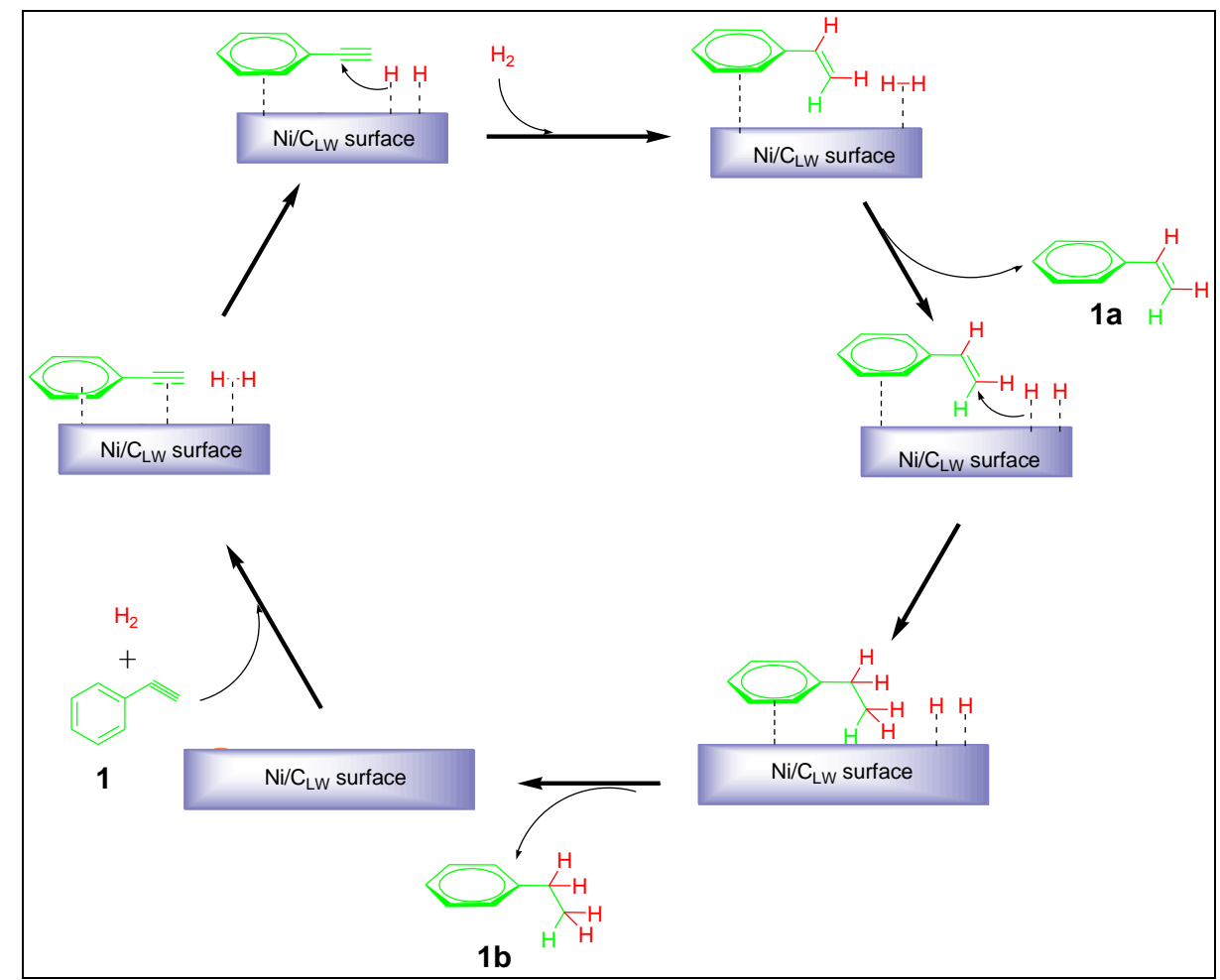

Figure 8. Proposed mechanism of Lignin based non-noble Ni catalyzed selective hydrogenation of phenyl acetylene

Based on the experiments and previously reported mechanism of alkyne hydrogenation, ${ }^{49}$ we proposed the mechanism of lignin based carbon material support $\mathrm{Ni}$ catalyzed hydrogenation of phenyl acetylene. As shown in Figure 8, the $\mathrm{H}_{2}$ and phenyl acetylene were both first adsorbed on the $\mathrm{Ni} / \mathrm{C}_{\mathrm{LW}}$ catalyst's surface. Then, one of $\mathrm{H}_{2}$ interacted with active $\mathrm{Ni}$ metal species and cleavage to give the $\mathrm{Ni}-\mathrm{H}$ species. At the same time, the phenyl acetylene which was absorbed on the catalyst's surface could undergo nucleophilic addition with the $\mathrm{Ni}-\mathrm{H}$ species and produce the alkenyl nickel intermediate. Then following the cleavage of the Ni-C bond of the alkenyl nickel intermediate, the $(Z)$-alkene product would be produced together with the Ni catalyst. While at the meantime, since nickel metal species had the strong hydrogenation ability, the 1a product also had the $\mathrm{C}=\mathrm{C}$ and aromatic bond with the physical electron properties, the 1a product and $\mathrm{H}_{2}$ could again absorb onto the catalyst's active metal species and generate the $\mathrm{Ni}-\mathrm{H}$ species. Then it would undergo the similar catalytic nucleophilic addition of $\mathrm{Ni}-\mathrm{H}$ species to the $\mathrm{C}=\mathrm{C}$ double bond, which generate the alkane product finally. During the hydrogenation of phenyl acetylene, the over-reduction is normally difficult to overcome, and generally, the alkane product easily occurs in the mixture of products. Here, using the facile synthesis lignin based carbon material supported nonnoble Ni catalysts, the adsorption and over-hydrogenation of olefins were inhibited, thereby achieving the selective production of olefins with high yields.

\section{Conclusions}

In summary, a facile directive synthesis method of cost-effective, high catalytic activity and environmentally friendly biomass carbon material supported non-noble Nickel catalyst were reported. And the novel catalysts were characterized by HRTEM, XRD, XPS, BET and evaluated their catalytic reactivity in the selective hydrogenation of phenyl acetylene. The biomass starting materials had a great effect on the catalysts' physical properties and catalytic hydrogenation. Compared with the catalyst prepared 
from shaddock peel, the catalysts $\mathrm{Ni} / \mathrm{C}_{\mathrm{L}}, \mathrm{Ni} / \mathrm{C}_{\mathrm{LW}}$ directly prepared from lignin had a denser layered and rod-shaped structure, and the catalysts' active nickel metal particles were evenly distributed in the carrier and had a larger pore volume. The reaction temperature, hydrogen pressure, reaction time, and solvent also had a great influence on the selective hydrogenation of phenyl acetylene using Ni-based catalysts. Under optimized mild reaction conditions $\left(2 \mathrm{Mpa} \mathrm{H}_{2}, 80^{\circ} \mathrm{C}, 4 \mathrm{~h}\right)$, the $\mathrm{Ni} / \mathrm{C}_{\mathrm{LW}}$ catalyst showed good catalytic activity with $97 \%$ conversion and $84 \%$ of desired product 1a selectivity. Here, the facile synthesized lignin-based carbon material supported non-noble metal $\mathrm{Ni}$ catalyst inhibited the adsorption of olefins, which prevent over-hydrogenation of styrene, and obtained the high-yield and selective production of styrene. This simple synthetic green, economical and sustainable biomass-based nickel-based catalyst provides a potential application prospect for the large-scale industrial application of biomass-based carbon material catalysts.

\section{Data availability}

Data supporting the findings of this study are available from the corresponding authors upon reasonable request.

\section{Acknowledgment}

This work was supported financially by the National Key R\&D Program of China (2018YFB1501500), National Natural Science Foundation of China (51976225).

\section{Author contributions}

J. G. L. supervised and designed the research. S.J.M performed the experiments and data analysis. S.J.M. and J. G. L. co-wrote the original manuscript. J. G. L. corrected and revised the manuscript. All authors discussed the results and assisted during manuscript preparation.

\section{Competing interests}

The authors declare no competing financial interests.

\section{References}

(1) Basimova, R. A.; Pavlov, M. L.; Myachin, S. I.; Prokopenko, A. V.; Askarova, A. V.; Kutepov, B. I.; Sychkova, S. A.Selective hydrogenation on palladium-containing catalysts of byproduct phenylacetylene present in industrial fractions of styrene. Pet. Chem. 2009, 49 (5), 360-365.

(2) Berenblyum, A. S.; Al-Wadhaf, H. A.; Katsman, E. A. Supported palladium nanomaterials as catalysts for petroleum chemistry: 2. Kinetics and specific features of the mechanism of selective hydrogenation of phenylacetylene in the presence of carbon-supported palladium nanocatalyst. Pet. Chem. 2015, 55 (2), 118-126.

(3) Dominguez-Dominguez, S.; Berenguer-Murcia, A.; Cazorla-Amoros, D.; Linares-Solano, A. Semihydrogenation of phenylacetylene catalyzed by metallic nanoparticles containing noble metals. $J$. Catal. 2006, 243 (1), 74-81.

(4) Dominguez-Dominguez, S.; Berenguer-Murcia, W.; Pradhan, B. K.; Linares-Solano, A. CazorlaAmoros, D., Semihydrogenation of phenylacetylene catalyzed by palladium nanoparticles supported on carbon materials. J. Phys. Chem. C 2008, 112 (10), 3827-3834.

(5) Duca, D.; Liotta, L. F.; Deganello, G. Selective Hydrogenation of Phenylacetylene on PumiceSupported Palladium Catalysts. J. Catal. 1995, 154 (1), 69-79.

(6) Duraczynska, D.; Serwicka,E.M.; Drelinkiewicz, A.; Olejniczak, Z. Ruthenium (II) phosphine/mesoporous silica catalysts: The impact of active phase loading and active site density on catalytic activity in hydrogenation of phenylacetylene. Appl.Catal.,A 2009, 371 (1-2), 166-172.

(7) Li, C.; Shao, Z. F.; Pang, M.; Williams, C. T.; Liang, C. H. Carbon nanotubes supported Pt catalysts for phenylacetylene hydrogenation: effects of oxygen containing surface groups on Pt dispersion and 
catalytic performance. Catal. Today 2012, 186 (1), 69-75.

(8) Weerachawanasak, P.; Praserthdam, P.; Arai, M.; Panpranot, J. A comparative study of strong metalsupport interaction and catalytic behavior of Pd catalysts supported on micron- and nano-sized $\mathrm{TiO}_{2}$ in liquid-phase selective hydrogenation of phenylacetylene. J. Mol. Catal. A: Chem. 2008, 279 (1), 133 139.

(9) Wilhite, B. A.; McCready, M. J.;Varma, A. Kinetics of phenylacetylene hydrogenation over Pt/gamma- $\mathrm{Al}_{2} \mathrm{O}_{3}$ catalyst. Ind. Eng. Chem. Prod. Res. Dev. 2002, 41 (14), 3345-3350.

(10) Spanjers, C. S.; Held, J. T.; Jones, M. J.; Stanley, D. D.; Sim, R. S.; Janik, M. J.; Rioux, R. M Zinc inclusion to heterogeneous nickel catalysts reduces oligomerization during the semi-hydrogenation of acetylene. J. Catal. 2014, 316, 164-173.

(11) Trimm, D. L.; Cant, N. W.; Liu, I. O. Y., The selective hydrogenation of acetylene in the presence of carbon monoxide over $\mathrm{Ni}$ and $\mathrm{Ni}-\mathrm{Zn}$ supported on $\mathrm{MgAl}_{2} \mathrm{O}_{4}$. Catal. Today 2011, 178 (1), 181-186.

(12) Tschan, M. J. L.; Suss-Fink, G.; Cherioux, F.; Therrien, B. Highly selective hydrogenation of carboncarbon multiple bonds catalyzed by the cation $\left[\left(\mathrm{C}_{6} \mathrm{Me}_{6}\right)_{2} \mathrm{Ru}_{2}\left(\mathrm{PPh}_{2}\right) \mathrm{H}_{2}\right]^{+}$: Molecular structure of $\left[\left(\mathrm{C}_{6} \mathrm{Me}_{6}\right)_{2} \mathrm{Ru}_{2}\left(\mathrm{PPh}_{2}\right)(\mathrm{CHCHPh}) \mathrm{H}\right]^{+}$, a possible intermediate in the case of phenylacetylene hydrogenation. Chem. Eur. J. 2007, 13 (1), 292-299.

(13) Komhom, S.; Mekasuwandumrong, O.; Praserthdam, P.; Panpranot, J. Improvement of $\mathrm{Pd} / \mathrm{Al}_{2} \mathrm{O}_{3}$ catalyst performance in selective acetylene hydrogenation using mixed phases $\mathrm{Al}_{2} \mathrm{O}_{3}$ support. Catal. Commun. 2008, 10 (1), 86-91.

(14) Wang, X. D.; Keane, M. A. Gas phase selective hydrogenation of phenylacetylene to styrene over $\mathrm{Au} / \mathrm{Al}_{2} \mathrm{O}_{3}$. J. Chem. Technol. Biotechnol. 2019, 94 (12), 3772-3779.

(15) Donphai, W.; Kamegawa, T.; Chareonpanich, M.; Yamashita, H. Reactivity of Ni-Carbon Nanofibers/Mesocellular Silica Composite Catalyst for Phenylacetylene Hydrogenation. Ind. Eng. Chem. Prod. Res. Dev. 2014, 53 (24), 10105-10111.

(16) Srimani, D.; Diskin-Posner, Y.; Ben-David, Y.; Milstein, D. Iron Pincer Complex Catalyzed, Environmentally Benign, E-Selective Semi-Hydrogenation of Alkynes. Angew. Chem. Int. Ed. 2013, 52 (52), 14131-14134.

(17) Johnson, C.; Albrecht, M. Z-Selective alkyne semi-hydrogenation catalysed by piano-stool Nheterocyclic carbene iron complexes. Catal. Sci. Technol. 2018, 8 (11), 2779-2783.

(18) Akl, D. F.; Ruiz-Ferrando, A.; Fako, E.; Hauert, R.; Safonova, O.; Mitchell, S.; Lopez, N.; PerezRamirez, J. Precursor Nuclearity and Ligand Effects in Atomically-Dispersed Heterogeneous Iron Catalysts for Alkyne Semi-Hydrogenation. Chemcatchem 2021, 13 (14), 3247-3256.

(19) Bock, C.; Paquet, C.; Couillard, M.; Botton, G. A.; MacDougall, B. R. Size-Selected Synthesis of PtRu Nano-Catalysts: Reaction and Size Control Mechanism. J. Am. Chem. Soc. 2004, 126 (25), 80288037 .

(20) Wu, C.; Chen, Y.; Shen, R.; Zhu, W.; Gong, Y.; Gu, L.; Peng, Q.; Guo, H.; He, W. J. N. R. The promoting effect of low-level sulfidation in $\mathrm{PdCuS}$ nanoparticles catalyzed alkyne semihydrogenation. Nano Res. 2018, 11 (9), 4883-4889.

(21) Cremer, P. S.; Su, X. C.; Shen, Y. R.; Somorjai, G. A. Ethylene hydrogenation on Pt(111) monitored in situ at high pressures using sum frequency generation. J. Am. Chem. Soc. 1996, 118 (12), 2942-2949. (22) Zhao, M. Q.; Crooks, R. M. Homogeneous hydrogenation catalysis with monodisperse, dendrimerencapsulated Pd and Pt nanoparticles. Angew. Chem. Int. Ed. 1999, 38 (3), 364-366.

(23) Saeys, M.; Reyniers, M. F.; Neurock, M.; Marin, G. B. Density functional theory analysis of benzene (De)hydrogenation on $\mathrm{Pt}(111)$ : Addition and removal of the first two H-atoms. J. Phys. Chem. B 2003, 107 (16), 3844-3855.

(24) Zhang, Z. L.; Zhu, Y. H.; Asakura, H.; Zhang, B.; Zhang, J. G.; Zhou, M. X.; Han, Y.; Tanaka, T.; Wang, A. Q.; Zhang, T.; Yan, N. Nat. Commun. 2017, 8 (1), 16100.

(25) Brandt, B.; Fischer, J. H.; Ludwig, W.; Libuda, J.; Zaera, F.; Schauermann, S.; Freund, H. J. Isomerization and hydrogenation of cis-2-butene on Pd model catalyst. J. Phys. Chem. C 2008, 112 (30), 11408-11420.

(26) Jujjuri, S.; Ding, E.; Hommel, E. L.; Shore, S. G.; Keane, M. A. Synthesis and characterization of novel silica-supported $\mathrm{Pd} / \mathrm{Yb}$ bimetallic catalysts: Application in gas-phase hydrodechlorination and hydrogenation. J. Catal. 2006, 239 (2), 486-500.

(27) Ornelas, C.; Aranzaes, J. R.; Salmon, L.; Astruc, D. "Click" dendrimers: Synthesis, redox sensing of $\mathrm{Pd}(\mathrm{OAc})_{2}$, and remarkable catalytic hydrogenation activity of precise Pd nanoparticles stabilized by 1,2,3-triazole-containing dendrimers. Chem. Eur. J. 2008, 14 (1), 50-64.

(28) Li, H. X.; Wang, W. J.; Deng, J. F. Glucose hydrogenation to sorbitol over a skeletal Ni-P amorphous alloy catalyst (Raney Ni-P). J. Catal. 2000, 191 (1), 257-260.

(29) Zinovyev, S.; Perosa, A.; Yufit, S.; Tundo, P. Hydrodechlorination and hydrogenation over RaneyNi under multiphase conditions: Role of multiphase environment in reaction kinetics and selectivity. $J$. 
Catal. 2002, 211 (2), 347-354.

(30) Li, Y. P.; Huang, X. M.; Zhang, Q.; Chen, L. G.; Zhang, X. H.; Wang, T. J.; Ma, L. L. Hydrogenation and hydrodeoxygenation of difurfurylidene acetone to liquid alkanes over Raney Ni and the supported Pt catalysts. Appl. Energy 2015, 160, 990-998.

(31) Xu, Y.; Long, J. X.; Liu, Q. Y.; Li, Y. B.; Wang, C. G.; Zhang, Q.; Lv, W.; Zhang, X. H.; Qiu, S. B.; Wang, T. J.; Ma, L. L. In situ hydrogenation of model compounds and raw bio-oil over Raney Ni catalyst. Energy Convers. Manage. 2015, 89, 188-196.

(32) Putra, R. D. D.; Trajano, H. L.; Liu, S. D.; Lee, H.; Smith, K.; Kim, C. S. In-situ glycerol aqueous phase reforming and phenol hydrogenation over Raney Ni (R). Chem. Eng. J. 2018, 350, 181-191.

(33) Putra, R. D. D.; Wijaya, Y. P.; Liang, R.; Smith, K. J.; Trajano, H. L.; Kim, C. S. The Effect of in Situ Phenol Hydrogenation with Raney Ni on the Fate of Hydrogen from Glycerol Aqueous Phase Reforming. Ind. Eng. Chem. Prod. Res. Dev. 2020, 59 (33), 14679-14688.

(34) Saadi, A.; Rassoul, Z.; Bettahar, M. M. Gas phase hydrogenation of benzaldehyde over supported copper catalysts. J. Mol. Catal. A: Chem. 2000, 164 (1-2), 205-216.

(35) Fan, Y. J.; Wu, S. F. A graphene-supported copper-based catalyst for the hydrogenation of carbon dioxide to form methanol. $J$. $\mathrm{CO}_{2}$ Util. 2016, 16, 150-156.

(36) Ye, R. P.; Lin, L.; Chen, C. C.; Yang, J. X.; Li, F.; Zhang, X.; Li, D. J.; Qin, Y. Y.; Zhou, Z. F.; Yao, Y. G. Synthesis of Robust MOF-Derived $\mathrm{Cu} / \mathrm{SiO}_{2}$ Catalyst with Low Copper Loading via Sol-Gel Method for the Dimethyl Oxalate Hydrogenation Reaction. ACS Catal. 2018, 8 (4), 3382-3394.

(37) De Bruyn, M.; Sener, C.; Petrolini, D. D.; McClelland, D. J.; He, J. Y.; Ball, M. R.; Liu, Y. F.; Martins, L.; Dumesic, J. A.; Huber, G. W.; Weckhuysen, B. M. Catalytic hydrogenation of dihydrolevoglucosenone to levoglucosanol with a hydrotalcite/mixed oxide copper catalyst. Green Chem. 2019, 21 (18), 5000-5007.

(38) Fan, Q. N.; He, S.; Hao, L.; Liu, X.; Zhu, Y.; Xu, S. L.; Zhang, F. Photodeposited Pd Nanoparticles with Disordered Structure for Phenylacetylene Semihydrogenation. Sci. Rep. 2017, 7 (1), 42172.

(39) Wind, T. L.; Falsig, H.; Sehested, J.; Moses, P. G.; Nguyen, T. T. M. Comparison of mechanistic understanding and experiments for CO methanation over nickel. J. Catal. 2016, 342, 105-116.

(40) Muroyama, H.; Tsuda, Y.; Asakoshi, T.; Masitah, H.; Okanishi, T.; Matsui, T.; Eguchi, K. Carbon dioxide methanation over Ni catalysts supported on various metal oxides. J. Catal. 2016, 343, 178-184.

(41) Song, S.; Yao, S. K.; Cao, J. H.; Di, L.; Wu, G. J.; Guan, N. J.; Li, L. D. Heterostructured Ni/NiO composite as a robust catalyst for the hydrogenation of levulinic acid to gamma-valerolactone. Appl. Catal., B 2017, 217, 115-124.

(42) Donphai, W.; Kamegawa, T.; Chareonpanich, M.; Yamashita, H. Reactivity of Ni-Carbon Nanofibers/Mesocellular Silica Composite Catalyst for Phenylacetylene Hydrogenation. Ind. Eng. Chem. Prod. Res. Dev. 2014, 53 (24), 10105-10111.

(43) Panwar, V.; Kumar, A.; Singh, R.; Gupta, P.; Ray, S. S.; Jain, S. L. Nickel-Decorated Graphene Oxide/Polyaniline Hybrid: A Robust and Highly Efficient Heterogeneous Catalyst for Hydrogenation of Terminal Alkynes. Ind. Eng. Chem. Prod. Res. Dev. 2015, 54 (45), 11493-11499.

(44) Chen, X.; Li, M.; Guan, J. C.; Wang, X. K.; Williams, C. T.; Liang, C. H. Nickel-Silicon Intermetallics with Enhanced Selectivity in Hydrogenation Reactions of Cinnamaldehyde and Phenylacetylene. Ind. Eng. Chem. Prod. Res. Dev. 2012, 51 (9), 3604-3611.

(45) Chen, X. A.; Zhao, A. G.; Shao, Z. F.; Li, C. A.; Williams, C. T.; Liang, C. H. Synthesis and Catalytic Properties for Phenylacetylene Hydrogenation of Silicide Modified Nickel Catalysts. J. Phys. Chem. C 2010, 114 (39), 16525-16533.

(46) Zhang, F.; Li, G. D.; Chen, J. S. Effects of raw material texture and activation manner on surface area of porous carbons derived from biomass resources. J. Colloid Interface Sci. 2008, 327 (1), 108-114. (47) Zhang, P.; Zhao, Z. B.; Dyatkin, B.; Liu, C.; Qiu, J. S. In situ synthesis of cotton-derived Ni/C catalysts with controllable structures and enhanced catalytic performance. Green Chem. 2016, 18 (12), 3594-3599.

(48) Duan, Y. N.; Song, T.; Dong, X. S.; Yang, Y. Enhanced catalytic performance of cobalt nanoparticles coated with a N,P-codoped carbon shell derived from biomass for transfer hydrogenation of functionalized nitroarenes. Green Chem. 2018, 20 (12), 2821-2828.

(49) Deng, D.; Yang, Y.; Gong, Y.; Li, Y.; Xu, X.; Wang, Y. Palladium nanoparticles supported on mpg$\mathrm{C}_{3} \mathrm{~N}_{4}$ as active catalyst for semihydrogenation of phenylacetylene under mild conditions. Green Chem. 2013, 15 (9), 2525-2531. 